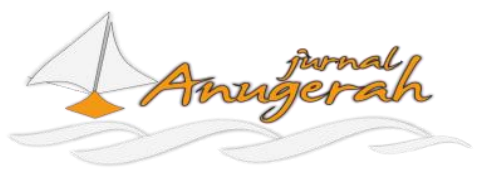

e-ISSN 2715-8179

https://ojs.umrah.ac.id/index.php/anugerah

\title{
Pendampingan Penyusunan Bahan Ajar Berbasis Multimedia bagi Kelompok Guru Sekolah Dasar di Desa Petunang Kabupaten Musi Rawas
}

\author{
Ely Susanti ${ }^{1}$, Muhammad Yusuf $^{2}$, Jeri Araiku $^{3 *}$, Scristia $^{4}$, Elika Kurniadi $^{5}$, Ruth Helen Simarmata ${ }^{6}$ \\ $1,2,3,4,5,6$ Universitas Sriwijaya, Palembang, Sumatra Selatan 30139, Indonesia \\ *e-mail korespondensi: jeriaraiku@ fkip.unsri.ac.id
}

Pengiriman: 15 April 2020; Diterima: 24 Mei 2020; Publikasi: 31 Mei 2020

DOI: https://doi.org/10.31629/anugerah.v2i1.2173

\begin{abstract}
Abstrak
Kegiatan pengabdian kepada masyarakat ini bertujuan untuk melatih guru SD di Desa Petunang, Kabupaten Musi Rawas untuk membuat bahan ajar berbasis multimedia dengan menggunakan aplikasi Microsoft PowerPoint dan Cabri 3D, menghasilkan bahan ajar berbasis multimedia, dan melihat respons peserta terhadap kegiatan pelatihan.Pengabdian ini penting agar guru di setiap daerah mampu untuk menghasilkan bahan ajar berbasis multimedia yang berkualitas dan mendorong perkembangan pembelajaran yang berorientasi pada keterampilan abad 21. Model yang dilakukan dalam kegiatan pengabdian ini adalah model pendampingan dengan metode pembagian alat dan bahan serta metode demonstrasi yang diikuti oleh 9 peserta dari SDN 1 Petunang. Hasil kegiatan menunjukan bahwa kegiatan berlangsung dengan baik serta guru-guru mampu membuat dua buah bahan ajar berbasis multimedia. Respons peserta pelatihan masuk ke dalam kategori memuaskan (3,129 dari 4) dengan rata-rata range kepuasan untukseluruh indikator sebesar 78,24\%. Respons tertinggi terdapat pada item respons pelatihan sangat bermanfaat bagi guru yaitu sebesar $97,22 \%$. Namun, respons untuk menggunakan multimedia sebagai bahan ajar cukup kecil dikarenakan keterbatasan fasilitas. Oleh sebab itu, diperlukan kerja sama berbagai pihak agar dapat memperbaiki sarana dan prasana pendukung agar dapat meningkatkan kualitas dan hasil belajar siswa.
\end{abstract}

Kata kunci: bahan ajar berbasis multimedia; Microsoft Powerpoint; Cabri 3D; pembelajaran matematika

\begin{abstract}
This community service activity aims to train elementary school teachers in Petunang Village, Musi Rawas Regency to create multimedia-based teaching materials using Microsoft PowerPoint and Cabri 3D applications, produce multimedia-based teaching materials, and see the teachers' responses to the training activities. This activity is important so that teachers in each region can produce qualified multimedia-based teaching materials and encourage the development of learning-oriented in $21^{\text {st }}$-century skills. The training was followed by 9 participants from SDN 1 Petunang. The results of the activity showed that the activity was going well and the teachers were able to make two multimediabased teaching materials. Training participants' responses were included in the impairment category $(3,129$ out of 4) with an average range of satisfaction for all indicators of $78.24 \%$. The highest response was found in the training response item of very beneficial for teachers, $97.22 \%$. However, the response to using multimedia as teaching material is quite small due to limited facilities. Therefore, a collaboration of various parties is needed to improve the facilities and supporting infrastructures to improve the quality and student learning outcomes.
\end{abstract}

Keywords: multimedia-based teaching material; Microsoft Powerpoint; Cabri 3D; mathematics instruction 


\section{Pendahuluan}

Teknologi sangat penting dalam pengajaran dan pembelajaran matematika karena dapat mempengaruhi bagaimana matematika itu diajarkan dan meningkatkan pembelajaran siswa (NCTM, 2000).Teknologi mendukung nilai pengetahuan dalam fase abstrak serta nilai kegunaan dalam fase konkret dari proses matematika, mengubah bahasa matematika, dan menyebabkan kualitas baru dari pemikiran matematika(Heugl, 2004).Integrasi teknologi dalam pengajaran menjadi tantangan pendidikan abad ke-21 sehingga perlu untuk membuat teknologi pendidikan harus memperluas kepemimpinan berpikiran maju dan kompetensi perencanaan mereka untuk memastikan penggunaan teknologi baru yang efektif (Mukminan, 2014; Mayes, Natividad, \& Spector, 2015).Ada banyak aplikasi yang dapat dimanfaatkan untuk membuat bahan ajar berbasis multimedia, seperti yang paling sederhana yaitu Microsoft PowerPoint dan aplikasi yang berbasis geometri seperti Cabri 3D (Hikmah \& Selvia, 2019; Waru \& Irfan, 2019).

Beberapa manfaat dari penerapan Microsoft PowerPoint dalam pembelajaran matematika antara lain guru dapat lebih memperhatikan kelas mereka karena mereka tidak harus membelakangi kelas ketika mereka menulis, guru bisa memperhatikan siswa yang tidak fokus membuat catatan dengan menjaga kontak mata dengan siswa di kelas, mempertahankan minat siswa selama pembelajaran, dan file salindia dapat dibagikan pada siswa agar dapat dipelajari secara mandiri di rumah (Lari, 2014). Selain itu, dengan menggunakan Cabri $3 D$, objek tiga dimensi seperti prisma, piramida, silinder, dan kerucut dapat dibangun, diputar, dan dilihat dari aspek tertentu pada layar dan juga dapat dibuat jaring-jaringnya pada layar. Prisma dan setengah bidang dapat berpotongan dan dengan demikian, objek tiga dimensi baru dapat dibentuk (Kosa \& Karakus, 2010).

Pemanfaatan teknologi seperti bahan ajar berbasis multimedia menjadi sangat penting terutama untuk tingkat sekolah dasar. Hal ini dikarenakan pemikiran siswa sekolah dasar mayoritas masih dalam tahap operasional konkret (Tall, 2002). Proses berpikir logis siswa sekolah dasar masih berdasar pada manipulasi fisik dari suatu obyek (Reiner \& Gilbert, 2000). Siswa dapat belajar matematika berdasarkan fakta yang jelas dan terlihat saat menggunakan alat bantu pengajaran (Biggs, 2011; Loewenberg, Thames, \& Phelps, 2008).Siswa akan lebih mudah untuk belajar dan memahami materi ketika proses pembelajaran tampak nyata dan menyenangan bagi mereka (Entwistle \& Ramsden, 2015; Olive, et al., 2010). Pemerintah telah melakukan upaya untuk membantu pengadaanbahan ajar berbasis multimedia di sekolah dasar di Indonesia, seperti website pembelajaran gratis. Namun, masih banyak sekolah-sekolah yang "tertinggal" karena kondisi topografi maupun kurangnya sarana prasarana pendukung seperti listrik, komputer, serta jaringan internet. Beberapa di antaranya adalah sekolah dasar yang terletak di Desa Petunang Kabupaten Musi Rawas, Sumatra Selatan.

Desa Petunang Kecamatan Tuah Negeri di Kabupaten Musi Rawas merupakan desa pertama kali yang dilalui ketika memasuki Kabupaten Musi Rawas dari Ibu Kota Provinsi Sumatera Selatan yaitu Kota Palembang.Desa Petunang merupakan bagian dari beberapa desa dengan banyak penduduk di Kabupaten Musi Rawas yang berada jauh dari pusat pemerintahan dan pendidikan.Secara umum, sekolah di desa tersebut tergolong sekolah dengan fasilitas yang sangat terbatas.Keterbatasan fasilitas dan kurangnya kegiatan pelatihan yang diikuti oleh guru membuat kemampuan guru dalam pemanfaatan IT masih sangat kurang. Hasil wawancara dengan kepala sekolah menunjukan bahwa kegiatan pelatihan yang diikuti guru, baik di tingkat kota atau tingkat provinsi, masih sangat kecil. Oleh karena itu, kemampuan guru dalam memanfaatkan IT dalam pembelajaran khususnya matematika masih sangat rendah. Oleh karena kurangnya kegiatan pelatihan yang diikuti oleh guru khusunya dalam pemanfaatan IT dalam proses pembelajaran matematika, maka dipandang perlu untuk melaksanakan kegiatan pengabdian dengan melibatkan guru matematika yang ada di Desa Petunang. Kegiatan ini akan dilaksanakan di salah satu sekolah di Desa Petunang, dengan melibatkan semua guru yang ada. Setelah melakukan wawancara awal, maka guru-guru tersebut membuat suratpermohonan untuk melaksanakan pendampingan penyususnan bahan ajar berbasis multimedia bagi kelompok guru sekolah dasar di Desa Petunang Kabupaten Musi Rawas.

Pengabdian mengenai pelatihan penggunaan Cabri 3D dan Microsoft PowerPoint dalam pengembangan bahan ajar telah dilakukan sebelumnya oleh beberapa pihak (Waru \& Irfan, 2019; Hikmah \& 
Selvia, 2019). Pada kegiatan-kegiatan tersebut, tim pengabdian fokus pada pelatihan penggunaan kedua aplikasi. Namun berdasarkan metode dan hasil yang diperoleh, kegiatan yang dilaksanakan tidak mencakup bagaimana respons peserta terhadap pendampingan yang dilakukan.Respons peserta pada suatu kegiatan pelatihan penting untuk dianalisis terutama sebagai dasar dalam melihat keberhasilan kegiatan, kepuasan peserta, dan sebagai dasar perbaikan dalam kegiatan selanjutnya (Hartono, Somakim, Pratiwi, Araiku, \& Nuraeni, 2019).

Berdasarkan uraian di atas, maka rumusan masalah dalam kegiatan pengabdian kepada masyarakat ini antara lain: (1) Guru-guru SD di Desa Petunang sangat jarang dalam mengikuti pelatihan pemanfaatan IT dalam pembelajaran, baik di tingkat kota maupun tingkat provinsi, (2) Guru-guru SD di Desa Petunang tidak memanfaatkan IT/multimedia dalam proses pembelajaran, salah satunya pembelajaran matematika, dan (3) Kegiatan pelatihan serupa yang telah dilakukan sebelumnya masih terfokus pada proses pelatihan, namun tidak melihat responss peserta pelatihan. Oleh sebab itu, tujuan dari dilaksanakan pengabdian kepada masayarakat ini adalah (1) Melatih guru-guru SD Desa Petunang dalam menyusun bahan ajar multimedia, (2) Menghasilkan bahan ajar multimedia yang telah dirancang oleh guru-guru SDN 1 Desa Petunang, dan (3) mengetahui responss guru-guru SD Desa petunang mengenai pelatihan penyususnan bahan ajar berbasis multimedia.

\section{Metode}

Khalayak sasaran dalam kegiatan pengabdian masyarakat ini adalah guru SDN1 Desa Petunang, Kabupaten Musi Rawas. Model pelaksanaan kegiatan pengabdian ini adalah model pendampingan untuk meningkatkan profesionalisme guru dalam pengembangan bahan ajar berbasis multimedia, di mana diperlukan pemahaman mengenai fungsi setiap perintah pada aplikasi PowerPoint dan Cabri 3D. Metode yang digunakan dalam pendampingan ini adalah pembagian alat (software Cabri 3D) dan bahan (modul penggunaan Microsoft PowerPoint dan Cabri 3D) serta metode peragaan yaitu pendampingan secara mandiri maupun kelompok kepada guru peserta. Demi mencapai tujuan pengabdian, kegiatan yang dilakukan adalah sebagai berikut: (1) melakukan wawancara kebutuhan calon peserta pendampingan mengenai jenis pengadian yang dilaksanakan; (2) agar tercapai tujuan melatih guru-guru dalam membuat bahan ajar berbasis multimedia, maka tim pengabdian membuat modul penggunaan Microsoft PowerPoint dan Cabri 3D untuk pengembangan bahan ajar berbasis multimedia. Selain itu, tim peneliti juga melaksanakan kegiatan pendampingan selama 2 sesi, yaitu sesi pendampingan penggunaan Microsoft PowerPoint selama 60 menit dan sesi pendampingan penggunaan Cabri 3D selama 90 menit; (3) agar tercapai tujuan menghasilkan bahan ajar berbasis multimedia oleh guru-guru, maka setelah memberikan pendampingan penggunaan Microsoft PowerPoint dan Cabri $3 D$ dengan membagi perserta menjadi beberapa kelompok.Tim peneliti memberikan waktu selama 210 menit untukmenyusun bahan ajar berbasis multimedia. Hasil yang diperoleh kemudian diperlihatkan kepada tim peneliti, (4) demi mengetahui respons guru terhadap kegiatan pengabdian, tim pengabdian menyusun angket respons mengenai pendampingan penggunaan aplikasi Microsoft PowerPoint dan Cabri 3D dan manfaatnya serta kegiatan pendampingan yang dilaksanakan, mengumpulkan data dengan menggunakan angket tersebut dan menganalisis hasilnya.

Demi melihat ketercapaian tujuan pengabdian antara lain, maka indikator ketercapaian yang diterapkan antara lain:

1. Kegiatan pengabdian berjalan sesuai dengan jadwal yang telah dirancang.

2. Guru-guru SDN 1 Desa Petunang mampu membuat bahan ajar dengan menggunakan Microsoft PowerPointdan Cabri 3D.

3. Rerata tingkat respons peserta pelatihan terhadap kegiatan dan modul pelatihan positif (minimal memuaskan). Demi melihat ketercapaian indikator ini, maka tahapan analisis yang dilakukan adalah sebagai berikut:

a. Mengumpulkan seluruh respons peserta pelatihan.

b. Menentukan rerata masing-masing item pernyataan dengan rumus berikut. 
JURNAL ANUGERAH, Mei 2020; 2(1): 1 - 11

e-ISSN. 2715-8179

$$
\bar{x}_{i}=\frac{\text { jumlah respons peserta pelatihan pada item } \mathrm{ke}-\mathrm{i}}{\text { banyak peserta pelatihan }}
$$

c. Menentukan rerata respons peserta pelatihan.

$$
\bar{X}=\frac{\sum_{1}^{n} \bar{x}_{i}}{n}
$$

Dimana, $i=1,2, \ldots, n$ (item pernyataan) dan $n=$ banyak item pernyataan.

d. Menentukan tingkat kepuasan peserta berdasarkan indikator pada Tabel 1 berikut.

Tabel 1

Indikator Tingkat Kepuasan Peserta (Behnke \& Kelly, 2011; Croasmun \& Ostrom, 2011)

\begin{tabular}{cc}
\hline Rerata & Tingkat kepuasan \\
\hline $3,25 \leq X \leq 4$ & Sangat Memuaskan \\
$2,5 \leq X<3,25$ & Memuaskan \\
$1,75 \leq X<2,5$ & Tidak Memuaskan \\
$1 \leq X<1,75$ & Sangat Tidak Memuaskan \\
\hline
\end{tabular}

\section{Hasil dan Pembahasan}

Pelaksanaan kegiatan pengabdian dibagi menjadi tiga tahap, yaitu persiapan, pelaksanaan, dan evaluasi.

\section{Tahap Persiapan}

Tahap persiapan ini dimulai dari wawancara akan kebutuhan calon peserta pendampingan. Berdasarkan hasil wawancara ini, maka tim memutuskan bahwa kelompok guru membutuhkan pendampingan untuk pembuatan bahan ajar berbasis multimedia. Setelah itu, pada tanggal 13 Mei 2019, SDN Petunang mengajukan permohonan untuk melakukan kegiatan pendampingan guru-guru di SDN Petunang Kabupaten Musi Rawas agar mampu menyusun Bahan Ajar Berbasis Multimedia. Tim menindaklanjuti permohonan dari SDN Kabupaten Musi Rawas yangmembutuhkan narasumber terkait Inovasi bagi Kelompok Guru Sekolah Dasar di Desa Petunang Kabupaten Musi Rawas yang mengalami kesulitan dalam menyusun bahan ajar berbasis multimedia. Disepakati bersama bahwa pelaksanaan kegiatan adalah tanggal 15 Oktober 2019 di SDN 1 Penutang Kabupaten Musi Rawas. Tim berkoordinasi dengan ketua MGMP agar dapat mengundang gurugurunya untuk dapat mengikuti kegiatan pendampingan tersebut.

Tim pengabdian kemudian mengajukan surat permohonan izin/surat tugas kepada Dekan FKIP Universitas Sriwijaya dalam rangka kegiatan tersebut. Setelah itu, tim mempersiapkan hal-hal yang dianggap penting untuk kelancaran pelaksanaan kegiatan. Tim pengabdian mempersiapkan modul penggunaan Cabri 3D. Modul tersebut diadopsi dari modul yang dikembangkan oleh Alpha Galih Adirakasiwi. Tampilan modul Cabri 3D dapat dilihat pada Gambar 1. 


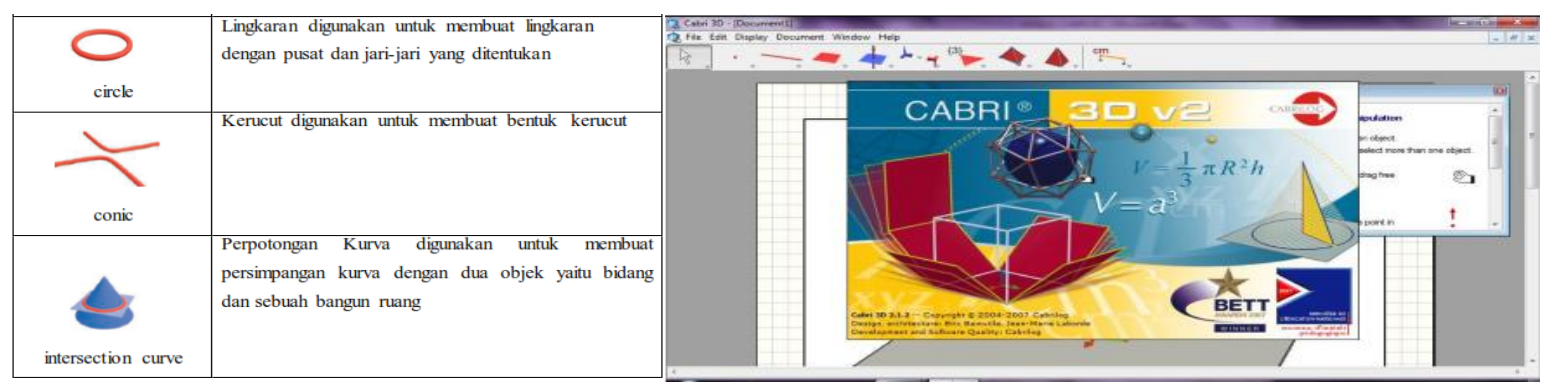

Gambar 1. Tampilan Cabri $3 D$

Selain itu, tim juga mempersiapkan angket respons yang akan dibagikan pada tahap evaluasi sebagai bahan pertimbangan untuk perbaikan kegiatan selanjutnya.

\section{Tahap Pelaksanaan}

Kegiatan pendampingan dilaksanakan di SD Petunang Kabupaten Musi Rawaspada tanggal 15 Oktober 2019. Jumlah peserta yang menghadiri kegiatan ini adalah 9 orang peserta, dengan rincian seperti pada Tabel 2.

Tabel 2

Daftar Peserta Pendampingan

\begin{tabular}{ccc}
\hline No & Nama & \multicolumn{1}{c}{ Asal Sekolah } \\
\hline 1. & AT & SDN 1 Petunang Kabupaten Musi Rawas \\
2. & YM & SDN 1 Petunang Kabupaten Musi Rawas \\
3. & ES & SDN 1 Petunang Kabupaten Musi Rawas \\
4. & TIS & SDN 1 Petunang Kabupaten Musi Rawas \\
5. & SM & SDN 1 Petunang Kabupaten Musi Rawas \\
6. & E & SDN 1 Petunang Kabupaten Musi Rawas \\
7. & LA & SDN 1 Petunang Kabupaten Musi Rawas \\
8. & ES & SDN 1 Petunang Kabupaten Musi Rawas \\
9. & RN & SDN 1 Petunang Kabupaten Musi Rawas \\
\hline
\end{tabular}

Berdasarkan kehadiran peserta tersebut, dapat dilihat bahwa seluruh guru yang berpartisipasi adalah guru SDN 1 Petunang Kabupaten Musi Rawas. Kurangnya partisipasi dari sekolah lain mungkin disebabkan beberapa hal, antara lain:

1) Kurangnya minat guru dalam mengikuti kegiatan yang bertujuan untuk meningkatkan profesionalitas guru terutama dalam membuat bahan ajar berbasis multimedia (Putri \& Citra, 2019).

2) Koordinasi guru-guru yang mungkin kurang maksimal sehingga informasi belum tersebar luas (Sulistyono, 2014).

3) Akses ke tempat pelatihan yang tidak mendukung (Asyari, 2020).

4) Hal lain, seperti kepentingan pribadi calon peserta yang tidak dapat ditinggalkan.

Namun setelah dilakukan tanya jawab dengan beberapa peserta yang hadir dan peserta yang tidak hadir (via telepon), diketahui penyebab ketidakhadiran guru dari SDN 2 Desa Petunang adalah karena pada hari yang 


\section{e-ISSN. 2715-8179}

sama memiliki acara di sekolahnya. Hal ini bisa menjadi masukan, baik bagi panitia maupun peserta pelatihan untuk dapat menentukan jadwal pada hari yang dapat diikuti oleh seluruh calon peserta.

Kendala yang dialami dalam pendampingan ini adalah fasilitas yang kurang memadai, seperti tidak adanya proyetor dan sound system, sehingga tim dosen harus meminjam sound system kepada ketua RT setempat. Selain itu, karena tidak adanya proyektor, maka kegiatan pendampingan dilakukan secara personal menggunakan laptop peserta.Kurangnya fasilitas dalam pembelajaran memiliki dampak yang besar terutama pada efektifitas dan efisiensi kegiatan belajar mengajar, proses adaptasi terhadap perkembangan teknologi, dan menunjang keterampilan siswa agar siap bersaing terhadap pesatnya teknologi (Wahono, 2014). Kegiatan pendampingan dapat dilihat pada Gambar 2 berikut.

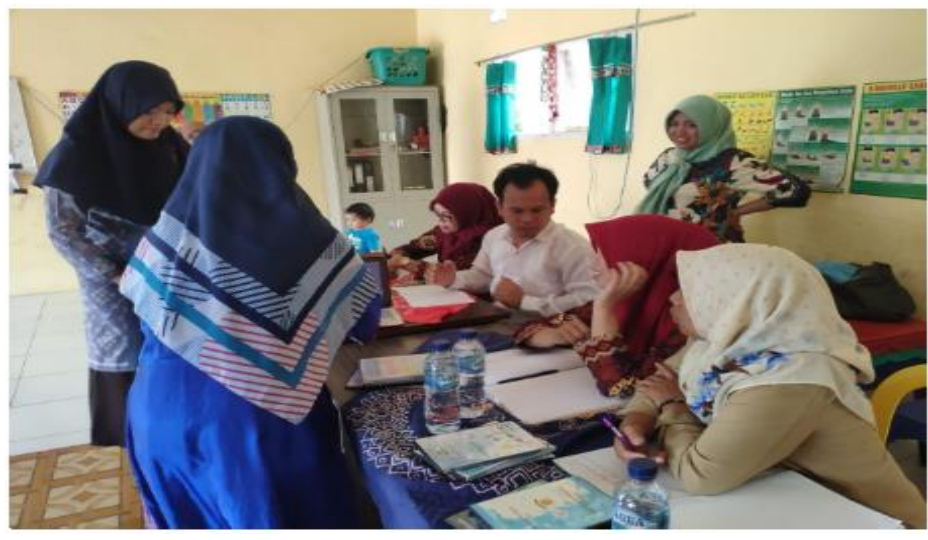

Gambar 2. Kegiatan pendampingan

Setelah dilakukan penjelasan mengenai aplikasi yang digunakan, peserta diminta untuk membuat bahan ajar berbasis multimedia dengan tim sebagai pendamping. Peserta dibagi menjadi dua kelompok, satu kelompok membuat bahan ajar dengan menggunakan Microsoft PowerPoint sedangkan kelompok lain membuat bahan ajar dengan menggunakan Cabri 3D. Kerja kelompok peserta pelatihan dapat dilihat pada Gambar 3.

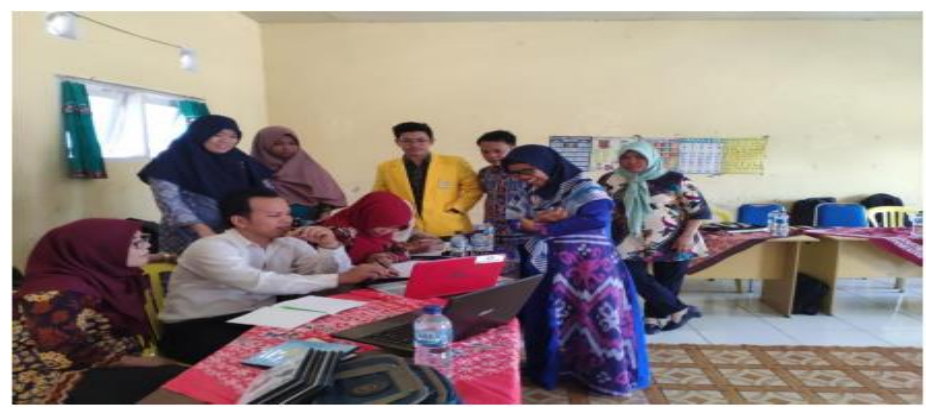

Gambar 3. Peserta membuat bahan ajar

Bahan ajar yang dihasilkan oleh peserta pendampingan dapat dilihat pada Gambar 4 dan gambar 5.

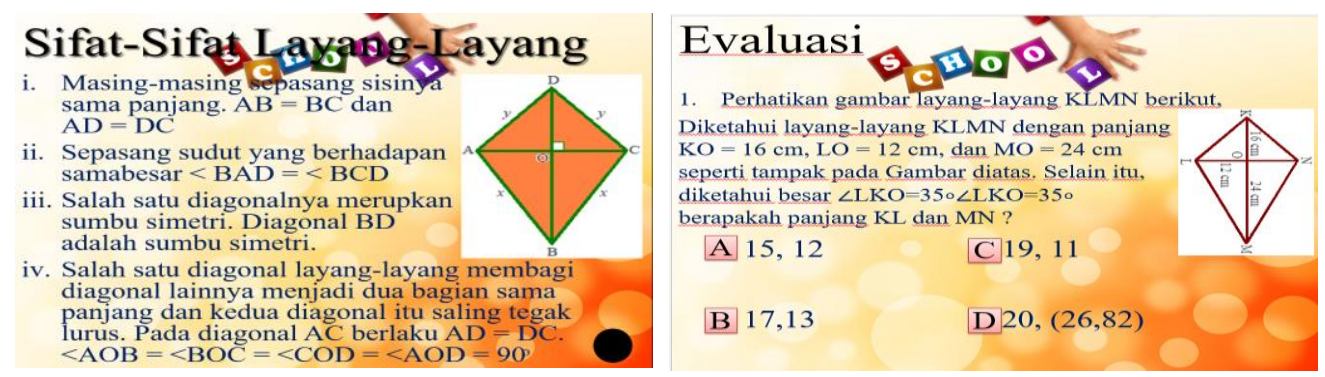

Gambar 4.Hasil pengembangan bahan ajar guru berbasis Microsoft PowerPoint 

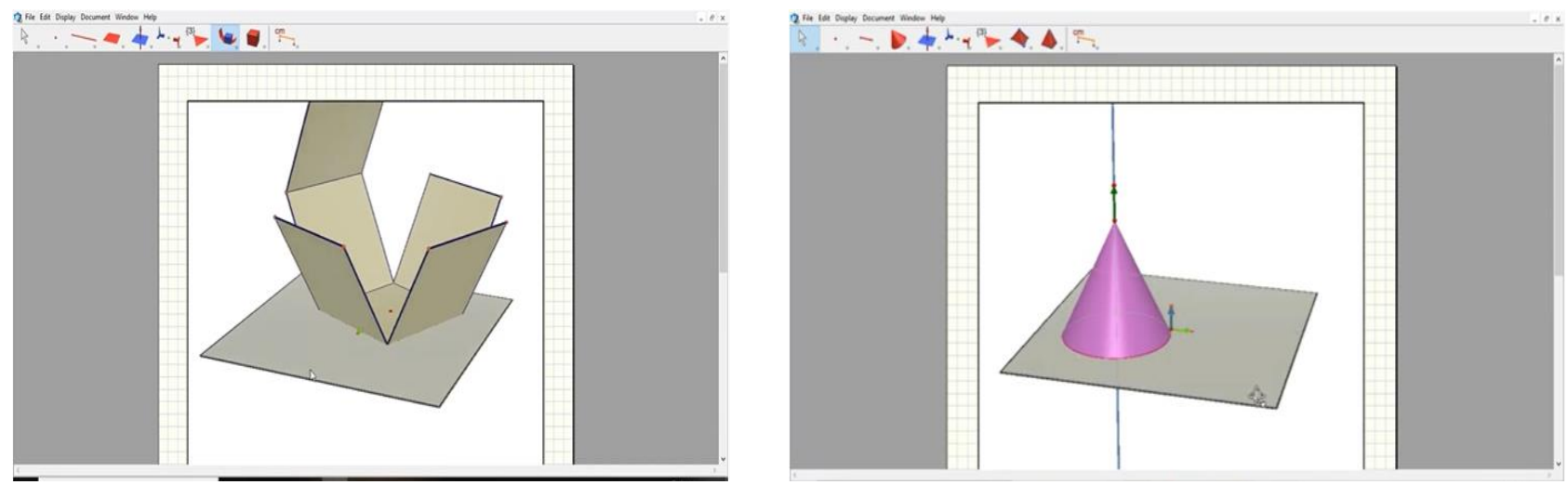

Gambar 5. Hasil pengembangan bahan ajar guru berbasis Cabri 3D

\section{Tahap Evaluasi}

Pada tahap evaluasi, tim pengabdian menyebarkan angket yang telah dipersiapkan pada tahap persiapan. Angket yang disiapkan terdiri atas 6 pernyataan. Hasil respons yang diberikan peserta pelatihan dapat dilihat pada Tabel 3 berikut.

Tabel 3

ResponsPeserta Pelatihan

\begin{tabular}{|c|c|c|c|}
\hline No & Indikator & $\begin{array}{c}\text { Nilai } \\
\text { Rata-rata }\end{array}$ & Persentase \\
\hline 1. & Pelatihan disajikan dengan jelas dan mudah dipahami & 3,67 & $91,67 \%$ \\
\hline 2. & Pelatihan sangat bermanfaat bagi guru & 3,89 & $97,22 \%$ \\
\hline 3. & $\begin{array}{l}\text { Saya akan menggunakan Microsoft PowerPoint dan Cabri } 3 D \text { untuk } \\
\text { mengembangkan bahan ajar }\end{array}$ & 3,11 & $77,78 \%$ \\
\hline 4. & Waktu pelatihan cukup & 2,78 & $69,44 \%$ \\
\hline 5. & Modul yang diberikan jelas & 2,56 & $63,89 \%$ \\
\hline 6. & $\begin{array}{l}\text { Modul yang diberikan sangat bermanfaat untuk membantu memahami } \\
\text { penggunaan multimedia }\end{array}$ & 2,78 & $79,44 \%$ \\
\hline & Rata-rata & 3,13 & $78,24 \%$ \\
\hline
\end{tabular}

\section{Pembahasan}

Berdasarkan hasil yang diperoleh dari kegiatan pelatihan, maka dapat dilihat ketercapaian indikator keberhasilan pelatihan sebagai berikut.

1. Terlepas dari kurangnya fasilitas penunjang dan jumlah peserta yang tidak memadai, pelaksanaan kegiatan pendampingan berjalan dengan cukup baik sesuai dengan jadwal pelaksanaan kegiatan yang telah dirancang sebelumnya. Hal ini terbukti dengan keterlaksanaan seluruh proses kegiatan sesuai dengan rencana yang telah ditentukan sebelumnya. Seluruh rangkaian kegiatan dapat dilihat pada Tabel 4. Namun, dampak yang ditimbulkan dari jumlah peserta yang tidak memadai antara lain: 


\section{e-ISSN. 2715-8179}

a. Kelompok yang dibentuk untuk membuat bahan ajar menjadi lebih sedikit sehingga bahan ajar yang dihasilkan hanya dua buah.

b. Kesimpulan yang diambil didasarkan pada 9 peserta pelatihan secara statistik tidak cukup kuat (Vishwakarma, 2017).

Oleh sebab itu untuk kegiatan selanjutnya, baik bagi panitia maupun peserta pelatihan untuk dapat menentukan jadwal pada hari yang dapat diikuti oleh seluruh calon peserta dengan komunikasi yang lebih intens seluruh pihak yang terlibat dengan proses pengabdian.

Tabel 4

Kegiatan Pendampingan

\begin{tabular}{cl}
\hline Waktu & \\
\hline $08.00-08.15$ & Pembukaan \\
$08.15-08.30$ & Menginstal aplikasi Cabri 3d \\
$08.30-09.30$ & Penyajian materi pembuatan bahan ajar menggunakan Microsoft PowerPoint \\
$09.30-11.00$ & Penyajian materi pembuatan bahan ajar menggunakan Cabri 3d \\
$12.00-13.00$ & Ishoma \\
$13.00-16.30$ & Pembuatan Bahan Ajar berbasis multimedia \\
$16.30-16.45$ & Pengisian Anget Respons \\
$16.45-17.00$ & Penutupan \\
\hline
\end{tabular}

2. Seluruh kelompok guru telah mampu untuk membuat bahan ajar berbasis multimedia dengan menggunakan Microsoft PowerPointdan Cabri 3d seperti yang ditunjukkan pada Gambar 4 dan 5 . Beberapa hal yang dapat menjadi faktor keberhasilan kegiatan antara lain adanya modul yang dapat membantu peserta pelatihan, antusiasme peserta pelatihan, pemateri melakukan pendampingan dengan baik, peserta telah memiliki soft skill yang baik, dan seluruh tim mampu untuk mengatasi kekurangankekurangan di lapangan dengan baik (Hartono, Lesmana, Permana, \& Matsun, 2018; Handayani, Husni, Lindawati, \& Tarmidi, 2017; Hartono, Somakim, Pratiwi, Araiku, \& Nuraeni, 2019).

3. Berdasarkan informasi dari Tabel 3, diperoleh nilai rata-rata sebesar 3,129 atau sebesar 78,24\%, yang berarti hasil yang diperoleh memuaskan (berdasarkan indikator pada Tabel 1). Kepuasan/persetujuan tertinggi berada pada indikator "pelatihan sangat bermanfaat bagi guru", yaitu sebesar 3,89. Hal ini mengindikasikan bahwa pelatihan yang diberikan sesuai dengan ekspektasi manfaat yang diperkirakan sebelumnya. Hal ini juga dapat berarti bahwa guru-guru di Indonesia memiliki kebutuhan dalam mengadopsi pembelajaran berbasis multimedia, terutama untuk menyesuaikan dengan perkembangan keterampulan abad 21 (Hartono, Lesmana, Permana, \& Matsun, 2018).Berdasarkan hasil angket respons yang diperoleh, terdapat 4 indikator yang memiliki nilai rata-rata terkecil, yaitu "Saya akan menggunakan Microsoft PowerPoint dan Cabri 3D untuk mengembangkan bahan ajar" sebesar 3,11, "waktu pelatihan cukup" sebesar 2,78, "modul yang diberikan jelas" sebesar 2,56, serta "Modul yang diberikan sangat bermanfaat untuk membantu memahami penggunaan multimedia" sebesar 2,78.

Pendamping kemudian melakukan wawancara untuk mengonfirmasi hasil pada indikator "Saya akan menggunakan Microsoft PowerPoint dan Cabri 3D untuk mengembangkan bahan ajar", kemudian diketahui alasan bahwa nilai yang diperoleh cukup rendah disebabkan oleh peserta yang berasal dari sekolah dengan 
fasilitas yang kurang memadai, sehingga cukup sulit untuk menerapkan Microsoft PowerPoint maupun Cabri $3 D$ dalam kegiatan pembelajaran mereka. Selain itu, cara menginstal Cabri $3 D$ yang cukup rumit sehingga mereka merasa kurang mumpuni untuk menginstal software tersebut secara mandiri. Hal ini akan berdampak pada kurang efektifnya materi yang akan disampaikan oleh guru (Putri \& Citra, 2019).Peserta juga merasa telah terbiasa untuk melakukan pembelajaran menggunakan papan tulis.

Pada indikator "waktu pelatihan cukup" diperoleh nilai sebesar 2,78 atau 69,44\%. Walaupun tingkat kepuasan peserta terhadap proses dan manfaat pelatihan cukup besar, namun waktu yang diberikan sebanyak 1 pertemuan masih dirasa sangat kurang. Hal ini disebabkan oleh aplikasi Cabri 3Dyang relatif baru bagi mereka.Selama pelatihan juga masih banyak guru yang kebingungan sehingga perlu mendapatkan waktu lebih untuk dibimbing.Oleh sebab itu, pelatihan yang bersifat pemanfaatan teknologi sebaiknya dilakukan secara berkala atau berkelanjutan, baik secara offline maupun online (Hartono, Somakim, Pratiwi, Araiku, \& Nuraeni, 2019)

Indikator selanjutnya yang memperoleh nilai sebesar 2,56 yaitu "modul yang diberikan jelas". Hal ini dikarenakan bukan semata-mata modul yang diberikan kurang jelas, namun karena sebagian besar dari mereka menggunakan Cabri 3D untuk pertama kali, sehingga untuk memahami isi modul cukup sulit dan tetap diperlukan bantuan pendamping untuk memahami fungsi setiap fasilitas yang terdapat dalam Cabri $3 D$. Mereka juga lebih senang untuk bertanya langsung mengenai caramengoperasikan aplikasi komputer kepada pendamping dibandingkan dengan membaca modul yang diberikan.Hal ini juga berkaitan dengan indikator terakhir yaitu "Modul yang diberikan sangat bermanfaat untuk membantu memahami penggunaan multimedia" yang mendapatkan skor sebesar 2,78. Meskipun demikian, peneliti percaya bahwa manfaat modul akan terlihat saat guru yang bersangkutan memerlukan informasi cara menggunakan Cabri $3 D$ di saat tidak ada pendamping untuk menjelaskan, sehingga guru tersebut akan berusaha memahami penggunaan Cabri $3 D$ dengan membaca modul yang telah dibagikan.

\section{Kesimpulan}

Berdasarkan hasil yang diperoleh, pelaksanaan pendampingan penyusunan bahan ajar berbasis multimedia berjalan lancar dan tepat waktu.Kendala-kendala yang dihadapi, seperti kekurangan fasilitas, dapat diatasi dengan baik karena adanya keterlibatan masyarakat sekitar dalam memenuhi kebutuhan seperti sound system.Guru-guru SDN 1 Desa Petunang dapat membuat bahan ajar berbasis multimedia dengan baik, hal ini dibuktikan dari adanya 2 produk hasil pengembangan bahan ajar yang telah dibuat kelompok guru. Selain itu, guru sudah dapat memaksimalkan penggunaan media pembelajaran yang bisadigunakan dalam pengembangan konsep pembelajaran matematika.Selain itu, respons guru terhadap kegiatan pelatihan memuaskan.Namun, terdapat respons yang kurang baik terutama pada waktu pelatihan dan pemanfaatan multimedia di kelas.

Selain menambah ilmu pengetahuan terutama dalam membuat bahan ajar berbasis multimedia bagi guru-guru di SDN 1 Desa Petunang. Kegiatan pengabdian kepada masyarakat ini juga memiliki beberapa kelebihan lain, di antaranya memberikan gambaran mengenai kondisi fasilitas yang terdapat pada Desa Petunang, Kabupaten Musi Rawas, di mana kesenjangan fasilitas ini dapat menjadi masukan bagi pihak terkait dalam peningkatan sarana dan prasarana pendidikan. Lebih jauh, berdasarkan respons guru, dapat menjadi masukan bahwa pelaksanaan pengabdian untuk guru-guru selanjutnya dapat difokuskan pada pemanfaatan teknologi dalam pembelajaran.

\section{Saran}

Saran yang dapat diberikan dalam kegiatan ini adalah guru-guru harus mulai membiasakan diri dalam memanfaatkan teknologi atau multimedia dalam membuat bahan ajar.Pemberian pelatihan dapat dilanjutkan secara berkala kepada guru-guru tersebut baik secara langsung (tatap muka) maupun online, sehingga masalahmasalah yang terindikasi saat melihat respons peserta pelatihan dapat teratasi dengan baik.Selain itu, dapat menjadi perhatian bagi seluruh stakeholder terutama pemerintah agar dapat memperhatikan fasilitas yang ada di sekolah-sekolah. Jika fasilitas yang memadai, maka motivasi guru untuk mengembangkan dan 
menggunakan bahan ajar yang berbasis multimedia akan lebih baik, sehingga proses dan hasil belajar siswa dapat meningkat.

\section{Ucapan Terima Kasih}

Tim pengabdian mengucapkan terima kasih yang kepada Universitas Sriwijaya yang telah mendanai kegiatan Pengabdian Kepada Masyarakat ini. Pengabdian ini didanai oleh Hibah Iptek dan Seni Budaya Universitas Sriwijaya tahun 2019. Selain itu, kami juga mengucapkan terima kasih kepada seluruh peserta yang telah berpartisipasi dalam kegiatan pendampingan pembuatan bahan ajar berbasis multimedia ini.

\section{Referensi}

Asyari, A. B. (2020).Upaya peningkatan mutu pendidikan di daerah terpencil. Retrieved from https://www.kompasiana.com/bayuasyari/5e931ac2d541df07625cc342/upaya-peningkatan-mutupendidikan-di-daerah-terpencil?page=all (diakses 12 April).

Behnke, A. O., \& Kelly, C. (2011). Creating programs to help latino youth thrive at school: The influence of latino parent involvement programs. Journal of Extension, 49(1), 1-13.

Biggs, J. B. (2011). Teaching for quality learning at university: What the student does, London: McGraw-Hill Education.

Croasmun, J. T., \& Ostrom, L. (2011). Using likert-type scales in the social sciences. Journal of Adult Education, 40(1), 19-22.

Entwistle, N., \& Ramsden, P. (2015). Understanding student learning, Abingdon: Routledge.

Handayani, A. S., Husni, N. L., Lindawati, \& Tarmidi. (2017). Pelatihan pembuatan modul pembelajaran audio visual dalam meningkatkan kreativitas dan efektivitas di MTs Muqimus Sunah Palembang. Prosiding Annual Research Seminar 2017, 3(1), 121-125.

Hartono, Lesmana, C., Permana, R., \& Matsun. (2018). Pelatihan dan pendampingan pembuatan media pembelajaran berbasis multimedia interaktif. Jurnal Tranformasi, 14(2), 139-147.

Hartono, Y., Somakim, Pratiwi, W. D., Araiku, J., \& Nuraeni, Z. (2019). Pendampingan penggunaan LaTeX untuk penulisan artikel ilmiah bagi dosen Universitas PGRI Palembang. Jurnal Anugerah, 1(1), 51 57.

Heugl, H. (2004). The Influence of technology in several roles of mathematics. Austrian Cent. Didact. Comput. Algebr, 1-35.

Hikmah, R., \& Selvia, N. (2019). Pelatihan Cabri 3D V2 untuk meningkatkan kreativitas guru dalam pembelajaran bangun ruang. Jurnal PKM: Pengabdian Kepada Masyarakat, 2(2), 155-161.

Kosa, T., \& Karakus, F. (2010). Using dynamic geometry software cabri 3d for teaching analytic geometry. Procedia Social and Behavioral Sciences, 2, 1385-1389. doi:10.1016/j.sbspro.2010.03.204

Lari, F. S. (2014). The Impact of using PowerPoint presentations on students' learning and motivation in secondary schools. Procedia Social and Behavioral Sciences, 98, 1672-1677. doi:10.1016/j.sbspro.2014.03.592

Loewenberg, B. D., Thames, M. H., \& Phelps, G. (2008). Content knowledge for teaching: What makes it special? Journal of Teacher Education, 59, 389.

Mayes, R., Natividad, G., \& Spector, J. (2015). Challenges for educational technologists in the 21st Century. Educ. Sci, 5(3), 221-237.

Mukminan. (2014). Tantangan pendidikan di abad 21. Seminar Nasional Teknologi Pendidikan, 1-10.

NCTM. (2000). Principles and sandards for school mathematics. Sch. Sci. Math., 47(8), 868-879.

Olive, J., Makar, K., Hoyos, V., Kor, L. K., Koshelva, O., \& Straber, R. (2010). Mathematical knowledge and practices resulting from access to digital technologies. Mathematics Education and TechnologyRethinking the Terrain, 133-177. 
Putri, S. D., \& Citra, D. E. (2019). Problematika guru dalam menggunakan media pembelajaran pada mata pelajaran IPS di Madrasah Ibtidaiyah Darussalam kota Bengkulu. IJSSE: Indonesian Journal of Social Science Education, 1(1), 49-54.

Reiner, M., \& Gilbert, J. (2000). Epistemological resources for thought experimentation in science learning. International Journal of Science Education, 22, 489.

Sulistyono, T. (2014). Model koordinasi pengelolaan guru PNS di Dinas Pendidikan Kota Yogyakarta Pada era otonomi daerah. Cakrawala Pendidikan, 33(1), 1-12.

Tall, D. (2002). The psychology of advanced mathematical thinking, Netherlands: Springer.

Vishwakarma, G. (2017). Sample size and power calculation, Faridabad: Clinical Development Services Agency (CDSA).

Wahono. (2014). Kualitas pembelajaran siswa SMK ditinjau dari fasilitas belajar. Jurnal Ilmiah Guru "COPE", 18(1), 66-71.

Waru, M. V., \& Irfan, A. (2019). Pelatihan pengembangan media pembelajaran berbasis multimedia pada kelompok MGMP matematika. MATAPPA: Jurnal Pengabdian Kepada Masyarakat, 2(2), 81-85. 